Universities Council on Water Resources

Journal of Contemporary Water Research \& Education

ISSUE 136, PAges 1-6, JUNE 2007

\title{
Water and Watersheds Research: Discovery and Broader Impacts
}

\author{
Penelope Firth ${ }^{1}$, Michelle Kelleher ${ }^{1}$, and Barbara Levinson ${ }^{2}$ \\ ${ }^{1}$ Division of Environmental Biology, National Science Foundation, Arlington, VA; ${ }^{2}$ Peer Review Division, National \\ Center for Environmental Research, U.S. Environmental Protection Agency, Washington, DC
}

$\mathrm{W}$ ater and watershed concerns integrate research challenges with human needs and they reflect the global urgency of many strategic, socioeconomic, and environmental crises. Issues of water availability (quantity, quality, timing), ecosystem functions and services, and human health and safety provide ample opportunity for new discoveries and the employment of existing knowledge to meet educators' and decision makers' needs.

\section{An Early History}

During 1992-93, several staff at the National Science Foundation (NSF) were convinced that there was a need within the agency for new and more flexible institutional arrangements for the science fields that supported research on fresh water and watersheds. The NSF had recently established a program in Hydrologic Sciences, but many other NSF units supported research on water and watersheds (e.g. Ecosystem Studies, Geography and Regional Science, Biological Oceanography, Ecology, Climate Dynamics, International Programs, Polar Biology and Medicine, and several others). Coordination between these programs did occur - typically bilaterally - but the research community interested in developing interdisciplinary or systemsapproach proposals was met with a confusing array of programs, none of which seemed appropriate to support this type of research.

Water and Watersheds was selected as a focus area for NSF's fiscal year 1995 (FY95) environmental research initiative. During summer 1994, program officers representing 10 Divisions in 6 Directorates participated in drafting an announcement. Many if not most of the Water and Watersheds investigators reported on the heady challenges of planning and implementing broadly interdisciplinary research projects. The NSF team was empathetic, because many of the challenges facing them echoed our own experience.

The timing of a special emphasis on Water and Watersheds coincided with the development of a research agenda produced by the academic community. "The Freshwater Imperative: A Research Agenda" (Naiman et al. 1995) was endorsed by the relevant professional societies, and was useful in defining specific areas for consideration in the Water and Watersheds competition.

At the same time, the NSF and the U.S. Environmental Protection Agency (EPA) began developing plans for a partnership to support extramural, investigator-initiated, peer-reviewed research. By the time the Memorandum of Understanding between NSF and EPA was signed in early December 1994, Water and Watersheds had been selected as one of three areas for joint FY95 funding. The interagency team worked through an absurdly compressed timeframe in order to release the first Announcement of Opportunity in February of 1995.

When the announcement appeared, a tremendous outpouring of interest occurred that nearly overwhelmed the staff. The NSF/EPA team had originally estimated that 400 proposals would be received. They kept revising this number upward as hundreds of emails, phone calls and letters were received prior to the May 1 deadline. The team was still sorting out administrative and management issues for the program while they contacted 
hundreds of potential panelists for the competition. Ultimately, 685 proposals were received for the first Water and Watersheds competition. The review panel held in June consisted of 105 experts from academia, government, and the private sector. The success rate was in the benthos at 4.8 percent.

That first entrepreneurial year was not over yet, however. Because internal administrative support was unavailable for the special competition, NSF employed an administrative support contractor. Cost overruns resulted in the contract being shut down during summer 1995. Unfortunately, the contractor had all of the declination jackets at their facility (this was before the days of electronic proposals) and they could not be touched until the issues were resolved and the contract was restarted in the fall. The declination delays engendered a huge volume of calls and emails from PIs anxious to see their reviews. The U.S. Federal government then shut down for about a month during 2005-2006. This was unrelated to the Water and Watersheds competition! However it did insert another delay into what had already been an intolerable proposal cycle.

\section{Lessons Learned}

The early history of the Water and Watersheds competition provided many useful lessons. In the years that followed, the NSF/EPA team, joined by U.S. Department of Agriculture in 1998, honed both the competition announcement and the management in such a way that fewer but more targeted proposals were received. Announcements emphasized a systems approach and general applicability of the research to watershed-scale questions ${ }^{1}$. In addition, proposals were required to be interdisciplinary, integrating physical, ecological, and social science (Figure 1).

While the NSF was interested in fostering fundamental research, and the EPA and USDA were concerned with furthering their agency missions, the Water and Watersheds competition advanced research that cut across the basic-applied continuum. Investigators were also asked to consider a community-based approach, that is, to communicate with local or regional governments and/or community groups ("stakeholders") in order to increase the relevance and dissemination of their findings to educators and decision makers.

As the program evolved, EPA assumed an increasing share of the management responsibilities.

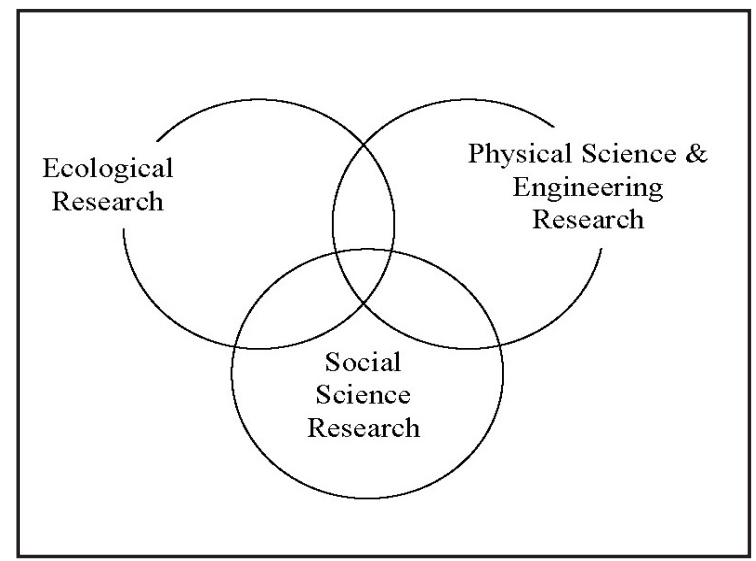

Figure 1. Venn diagram illustrating the conceptual approach for Water and Watersheds. Proposals in the center of the Venn diagram were most competitive.

Progress reviews were held in 1996 (Alexandria, VA), 1998 (Corvallis, OR), 1999 (Silver Spring, MD), and 2001 (San Francisco, CA) in order to enhance cross-fertilization between projects and to deliver findings directly to potential users. The URL for the proceedings of the 2001 progress review is: http://es.epa.gov/ncer/publications/workshop/ pdf/2001_water_watersheds.pdf. The proceedings of prior progress reviews are not available via the web.

A cogent and comprehensive analysis of lessons learned from Water and Watersheds was sponsored by the EPA in 2001 (http://es.epa.gov/ ncer/publications/workshop/pdf/water_watershed lessons2001.pdf). The authors pointed out that environmental issues are broader than disciplinary boundaries, and that interdisciplinary research is changing environmental science. The participants concluded that social sciences contributions were a major strength of the program and that stakeholder input and communication were invaluable to the positive outcomes of these projects. Watershed management requires a large- (i.e. watershed-) scale perspective, and both natural and human dimensions need to be considered to advance fundamental understanding and manage resources wisely.

The management lessons learned in this analysis were also enlightening, and will be familiar to all who have led or participated in broadly-interdisciplinary projects. They covered the personnel issues such as the requirement for a strong leader and a great lieutenant; the need to "park egos at the door;" the rule of inclusiveness and commitment; and the 
need for younger faculty to maintain disciplinary expertise in order to advance their personal careers. Administrative lessons included the need for a management plan parallel to the research plan; the startlingly hefty amount of time needed for project management and interaction among team members; and the unspoken truth that three years is too short for an interdisciplinary research project.

The report made recommendations for enhancing communication within and among Water and Watersheds project teams. Other recommendations covered minimizing administrative burdens, reducing institutional constraints, and measuring success. In this latter area, the participants recommended considering how projects advanced education, employment, outreach, and use of project results by decision makers and other audiences. We were able to follow up on some of these recommendations in a project carried out by M. Kelleher in 2003 (below).

\section{Discovery and Broader Impacts}

Most of the projects supported by the Water and Watersheds competition advanced our fundamental understanding of watersheds. Many projects also had strong impacts beyond the intellectual merit of the research itself. Support for education and outreach efforts were found in almost every project. A variety of projects also were connected to the information needs of decision makers.

During 2003, M. Kelleher had conversations with a number of Water and Watersheds Principal Investigators (PIs), seeking to revisit some of the completed early awards. The objective of her project ${ }^{2}$ was to find out what kinds of long-term outcomes the support for Water and Watersheds research had netted. We should note that this was a luxuriously novel approach for NSF at least, as the staff usually do not have the time to work on a project like this.

Kelleher's conversations sought to get a qualitative idea of the long-term outcomes of the Water and Watersheds program in terms of education, human capital, support of decisionmaking, and advancing theoretical understanding in the field (Table 1). She sought not just hard data, but personal experiences and observations surrounding the research - qualitative material not available in the typical final project reports. She listed a single lesson learned in her report: Plan to spend much longer than you plan to spend on the project.
Kelleher had conversations with a subset of the Water and Watersheds PIs, mainly those who were available and willing to talk with her during the limited term of her project. In the areas of education and human capital she found that virtually all had hosted graduate students on their projects, and most had also trained postdocs and undergraduate students as well. These individuals had generally had the opportunity to publish or present at professional meetings. Several investigators had ventured into the K-12 arena, holding science workshops, providing science assistance and lectures for high school classes, and presentations for teachers. About half of the investigators had used Water and Watersheds projects in their curricula, and many had integrated portions into graduate programs at their institutions. At least one investigator hosted field and laboratory experiences for science writers.

As a part of these conversations, Kelleher got an idea of the breadth and nature of collaboration in Water and Watersheds projects. She found that leveraged funding and in-kind support was a common feature, and most of the projects indicated that they had participants in multiple departments and/or institutions. Local, state, and federal government personnel were participants in several projects, and a few included representatives from the business or consulting communities, as well as non-governmental organizations. International connections were relatively limited due to programmatic constraints: NSF funding could be used for international projects, but EPA or USDA funds could not.

Virtually everyone Kelleher talked with had multiple publications in the primary literature. Many had also edited books, developed websites, databases or software, or archived physical collections. Public products included presentations, public workshops, TV and radio appearances, and newspaper articles. The investigators had participated in a wide variety of products for decision makers. These included presentations, speeches or tours for federal, state and local officials, and international audiences; domestic and international conference participation; consulting services on advisory committees and in watershed restoration; the development of decision support systems, and predictive simulation software.

Every individual that Kelleher talked with felt that their interdisciplinary project had made contributions to advancing theoretical understanding in a way that would not have been possible by disciplinary inquiry 
alone. Interdisciplinary modeling - both conceptual and computational - was a feature of multiple projects. Her project did not delve into the details of the science, but the investigators with whom she spoke uniformly supported a systems approach and integration of approaches across multiple disciplines.

\section{The Contributions to this Issue of JCWRE}

The authors of this issue were all supported in the early years of the Water and Watersheds competition. For this issue - the brainchild of Editor Chris Lant - they were asked to develop insightful and pithy essays that discussed the outcomes of their projects. In particular, we asked them to focus on information generated that was used by decision makers and/or educators. Almost every project reported pathbreaking interdisciplinary research at scales not previously employed. Many investigators reported that they did not fully anticipate the additional time and effort working to integrate across disciplines would entail.

Sparks and Braden linked hydraulic and ecological models and economic analyses to evaluate alternatives for selective reconnection of a large river and its floodplain. They were particularly interested in understanding how flood damages could be reduced and natural ecosystem services could be restored by naturalizing riverfloodplain systems. Their project, like many others, required "adjustments" in order to allow team members to contribute effectively to a multidisciplinary effort and to address issues that were important to stakeholders. In addition to many other accomplishments and discoveries, the team developed an exceptionally useful biologically meaningful hydrologic parameter. The findings of this project have had immediate regional application and are being used as a model for naturalization projects undertaken by a variety of state and federal agencies. Broader impacts have also included inclusion of results in educational efforts and curriculum development for undergraduates and graduate students.

Sweeney and Blaine, at the Stroud Water Research Center, studied how stream ecosystems respond differently to streamside riparian areas planted in grass vs. trees. They found that streams with grass buffers showed significant channel narrowing, compromising the in-stream processing of pollutants, the ability of the stream to support historic fish populations, and the quality of organic matter found in the stream. There was resounding evidence that riparian forests won hands down over grass buffers when considering the overall health of a stream, and its ability to deliver services to people. They went on to mount a public education effort and to reach out to decision-makers with their findings and the likely implications of different policy options. The authors noted that communication and language were exceptionally important: the language used by scientists is rarely meaningful to the general public, and may be unintelligible to resource managers and other decision makers. The findings of this study have already diffused broadly into public policy at the state and regional level.

Richey and Fernandes studied the dynamics of large river basins in the Pacific Rim. They

Table 1. Areas discussed with Water and Watersheds PIs in seeking qualitative long-term outcomes of the program.

\begin{tabular}{ll}
\hline Area & Examples \\
\hline Education & $\begin{array}{l}\text { Outcomes of research used by institutions in curriculum or other educational compo- } \\
\text { nents; outcomes of research used in teaching materials such as textbooks, workbooks, } \\
\text { CD ROMS, electronic modules, web pages, or videos; research outcomes used or ac- } \\
\text { cessible via web links to/from educational/institutional websites other than that of the } \\
\text { project } \\
\text { research findings used in media articles, press releases or other public venue; research } \\
\text { findings distributed directly to decision makers; research team involved in processes of } \\
\text { decision making, policy making or similar consultation } \\
\text { Decision making } \\
\text { research project contributions to the studies or careers of the student participants; } \\
\text { contributions to the careers of the PIs; known influence of project on other investigators } \\
\text { and students } \\
\text { research project contributions to innovations and advancing the science in the fields of } \\
\text { study; contributions to modeling or other capabilities in the fields of study }\end{array}$ \\
\hline
\end{tabular}


understood that the abundant research findings from small streams could not be scaled up to the scale of large rivers without taking into account a variety of complexities and threshold phenomena. Their project sought to understand the landscape and hydrologic dynamics of large watersheds in order to assess the vulnerability of specific sectors to potential scenarios of climate and land-use change. They developed a strategy for taking fundamental information and translating it into water resource information for regional-scale management. Importantly, they wished to provide this understanding to decision makers in developing countries. Richey and colleagues engaged multiple regional stakeholders and decision makers in using the Decision Information Framework that they had developed. They used these interactions to fine-tune the instrument so that it could be applied more effectively. A number of their findings on the effects of land use change were unanticipated, and they have now spent well over a decade in tireless efforts to educate managers and other decision makers around the globe as to the likely outcomes of different watershed-scale scenarios.

Santelmann and colleagues studied alternative futures for agricultural landscapes in the U.S. corn belt that could result in 2025 from different sets of policy choices. They linked high-resolution representations of alternative future landscapes to spatially-explicit modeling and evaluation tools for comparison across multiple endpoints. Santelmann describes the time of the Water and Watersheds competition as the period when interdisciplinary ecosystems research came of age. In her project, like many others, the investigators from multiple disciplines had to develop a common language and understanding. She, like many of us, did not fully anticipate the additional time that interdisciplinary effort would require. The future scenario approach pioneered by Santelmann and others has now been used in many research projects as well as by real-world decision makers to explore the entangled issues relating to humans, water, and watershed ecosystems. The approach and outcomes of her project have been widely disseminated, and are showing up in educational, outreach and decision making applications both nationally and internationally.

Pickett et al. studied the urban watershed of Baltimore, Maryland. Their study pioneered urban applications of the watershed ecosystem approach that had been developed in natural areas. In particular, they were interested in how urban watersheds function under changing conditions of land use and climate change. Their project leveraged the Water and Watersheds award with a simultaneous award for an Urban Long-Term Ecological Research site - effectively extending the scale and duration of their project, as well as its connectivity to the needs of educators and decision makers. The investigators made numerous advances to our fundamental understanding of urban riparian zones, land cover theory, social theory for urban watersheds, the role of complex household structure, and stormwater management. They also can point to a powerful feedback that they developed between research and decision making for this urban area, and to numerous educational achievements that were spawned by their work.

Meo and colleagues undertook a project on stakeholder-informed decision making for the Illinois River, along the boundary of Arkansas and Oklahoma. They were particularly interested in understanding development impacts in the watershed and the views and values of various stakeholders in the context of management alternatives. Their project incorporated modeling, biological impact assessment, economic impact assessment, and the identification of stakeholder concerns. A visualization-rich watershed-management decision support system was used to facilitate understanding by stakeholders of the complex relationships in the watershed. A key finding of the study was that asynchronous policy dialogues that are informed by intensive assessments of stakeholders' concerns, preferences, and knowledge, can be successful in contexts dominated by distrust, controversy, and factual uncertainty. In addition to scholarly publications, team members participated in a variety of activities that broadened the impact of their work. These included authoring book chapters, presenting seminars, and interacting with policy makers.

Hunt et al. performed a case study on acid rain research and policy. Specifically, they evaluated the effectiveness of a stakeholder assessment at the local level concerning the relevance of findings from an ongoing acid rain research program. Project participants were challenged at the outset to identify the stakeholders in a meaningful way. They also identified a set of broad questions, one 
of which could have applicability in virtually every Water and Watersheds project: Are the areas of greatest scientific uncertainty also those areas where the value of improved knowledge is highest? As it turned out, local stakeholders such as representatives of the forest industry, had very different perceptions and values than those at the regional/national/international scale of the acid rain problem. In addition to the theoretical advances made by this team, information from the project has been used by the U.S. EPA in its assessment of the 1990 Clean Air Act Amendments and the findings may thus influence future federal policy and legislation.

\section{Conclusions}

At its inception, the Water and Watersheds competition was one of the most novel grant opportunities available from the Federal government. The combination of broadly interdisciplinary research, the watershed scale, the focus on inclusion of stakeholders in projects, and the wide dissemination of findings to educators and decision makers made every project stunningly complex, challenging, and notable. We salute the authors of this issue, and the many others who participated in making Water and Watersheds a success.

\section{Endnotes}

1. The goal of the competition was to develop an improved understanding of the natural and anthropogenic processes that govern the quantity, quality, and availability of water resources in natural and human-dominated systems, and an understanding of the structure, function, and dynamics of the terrestrial and aquatic ecosystems that comprise watersheds. Interdisciplinary research was required, and the most competitive proposals were those that helped integrate multiple goals of NSF, EPA and/or USDA programs and addressed questions that were comprehensive in scale and transferable in scope. High priority was given to public and/or stakeholders' involvement from the development of the research questions to the dissemination of the results.

2. The Kelleher project was completed during a summer internship at NSF sponsored by the Hispanic Association of Colleges and Universities.

\section{Author Bios and Contact Information}

Penelope Firth is the Acting Division Director for NSF's Environmental Biology Division. She created and chaired the interagency ad hoc Freshwater Imperative coordinating council for several years, was the chief NSF architect for the NSF/EPA Partnership for Environmental Research, and was the lead Program Director for the Water and Watersheds competition. As a follow-on to Water and Watersheds, she helped create and lead an interdirectorate NSF program entitled Dynamics of Coupled Natural and Human Systems. Dr. Firth can be contacted at NSF Division of Environmental Biology, 4201 Wilson Blvd., Arlington, VA 22230, Phone: 703.292.8480, E-mail: pfirth@nsf.gov.

Michelle Kelleher is the Division Science Assistant for NSF's Environmental Biology Division. She participated in an internship during the summer of 2003 during which she spoke with a number of Water and Watersheds PIs about the outcomes and broader impacts of their research. Ms. Kelleher can be contacted at NSF Division of Environmental Biology, 4201 Wilson Blvd., Arlington, VA 22230, Phone: 703.292.8480, E-mail: mkellehe@, nsf.gov.

Barbara Levinson is the Acting Division Director for EPA's Peer Review Division within the Office of Research and Development, National Center for Environmental Research. She was the Program Manager for Ecosystems Research for the Science to Achieve Results (STAR) program for approximately eight years. Ms. Levinson can be contacted at EPA, 1200 Pennsylvania Ave. NW, (8701F), Washington, DC 20460, Phone 202-343-9720, E-mail: Levinson.Barbara@EPA.gov.

\section{References}

EPA Science Advisory Board. 2001. The Science to Achieve Results (STAR) Water and Watersheds Grants Program: An EPA Science Advisory Board Review. EPA-SAB-EPEC-02-001. http://www.epa.gov/sab/ pdf/epec02001.pdf. 